\title{
Ligand-Assisted Solid-State Transformation of
}

\section{Nanoparticles}

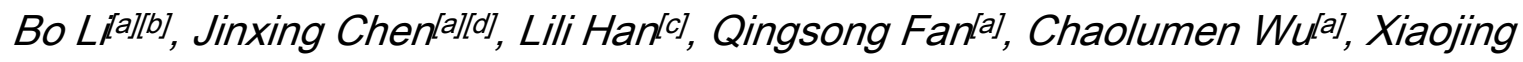

Wang ${ }^{[a]}$, Michael Lee $e^{[a]}$, Huolin L. Xin ${ }^{[c]}$, Zhiwu Han ${ }^{[b]}$, Yadong Yin ${ }^{[a], *}$

[a] Department of Chemistry, University of California Riverside, Riverside, CA 92521,

USA

${ }^{[b]}$ Key Laboratory of Bionic Engineering (Ministry of Education, China), Jilin University,

Changchun, Jilin 130022, P. R. China

${ }^{[c]}$ Department of Physics and Astronomy, University of California Irvine, Irvine, CA

92697, USA 
${ }^{[d]}$ Institute of Functional Nano \& Soft Materials (FUNSOM), Jiangsu Key Laboratory for Carbon-Based Functional Materials \& Devices, Soochow University, Suzhou, Jiangsu 215123, P.R. China

* Corresponding Author.

E-mail address: yadong.yin@ucr.edu. Fax: +1-951-827-4713 
Synthesis of $\boldsymbol{\beta}$-FeOOH ellipsoids. ${ }^{1}$ The synthesis of $\beta$-FeOOH ellipsoids is based on a previously reported method with minor revisions. $0.2 \mathrm{M} \mathrm{FeCl}_{3} \cdot 6 \mathrm{H}_{2} \mathrm{O}$ and $10 \mathrm{~g} \mathrm{CTAC}$ were dissolved in 100 $\mathrm{ml}$ water. Then, the solution was transferred into a $250 \mathrm{~mL}$ narrow-necked bottle and was heated at $87{ }^{\circ} \mathrm{C}$ for 24 hours. The final product was washed with water 3 times and collected by centrifugation. At last, the precipitate was dispersed in $25 \mathrm{~mL}$ of water.

Synthesis of $\boldsymbol{\beta}$-FeOOH nanorods. ${ }^{2} 0.1 \mathrm{M} \mathrm{FeCl}_{3} \cdot 6 \mathrm{H}_{2} \mathrm{O}$ was dissolved in $400 \mathrm{~mL}$ distilled water. Then the solution was heated at $60{ }^{\circ} \mathrm{C}$ for 4 days. In the initial stage of the heating process, the temperature rises at a rate of $0.2{ }^{\circ} \mathrm{C} \cdot \mathrm{min}^{-1}$ until it rises to $60{ }^{\circ} \mathrm{C}$. The product was removed by centrifugation and washed with water twice and then dispersed in $25 \mathrm{~mL}$ water for future use.

Synthesis of Prussian blue nanocubes. ${ }^{3}$ The synthesis followed a previously reported method. $113.14 \mathrm{mg}$ potassium ferricyanide and $3 \mathrm{~g}$ of PVP $(\mathrm{Mw} .40,000)$ were added to a $40 \mathrm{~mL} 0.1 \mathrm{M} \mathrm{HCl}$ solution. After stirring at room temperature for $30 \mathrm{~min}$, the system was heated at $80^{\circ} \mathrm{C}$ for 20 hours. The blue product was then collected by centrifugation and dispersed in $25 \mathrm{~mL}$ water for future use. Synthesis of $\mathbf{C o}(\mathbf{O H})_{2}$ nanoplates. ${ }^{4} \mathrm{Co}(\mathrm{OH})_{2}$ nanoplates were synthesized based on a previous report with some modifications. Typically, $0.48 \mathrm{~g}$ of $\mathrm{CoCl}_{2}$ was dissolved in $0.2 \mathrm{~g}$ of PVP $(\mathrm{Mw}=55,000)$ and $72 \mathrm{~mL}$ of $\mathrm{H}_{2} \mathrm{O}$, followed by adding $0.56 \mathrm{~g}$ of hexamethylenetetramine and $8 \mathrm{~mL}$ of ethanol. The mixture was heated at $95^{\circ} \mathrm{C}$ for $2 \mathrm{~h}$. The products were collected by centrifugation, washed with $\mathrm{H}_{2} \mathrm{O}$ and redispersed in $40 \mathrm{~mL}$ of $\mathrm{H}_{2} \mathrm{O}$.

Synthesis of $\mathbf{N i}(\mathbf{O H})_{2}$ nanoplates. ${ }^{5}$ To synthesize the $50 \mathrm{~nm} \mathrm{Ni}(\mathrm{OH})_{2}$ nanoplates, an aqueous solution of $10 \mathrm{~mol} \cdot \mathrm{mL}^{-1} \mathrm{Ni}\left(\mathrm{NO}_{3}\right)_{2}$ and $20 \mathrm{~mol} \cdot \mathrm{mL}^{-1} \mathrm{NH}_{3} \cdot \mathrm{H}_{2} \mathrm{O}$ was heated in an oven at $90^{\circ} \mathrm{C}$ for 2 hours. And then the solution was washed with water several times and dispersed in $25 \mathrm{~mL}$ water for the next step. 

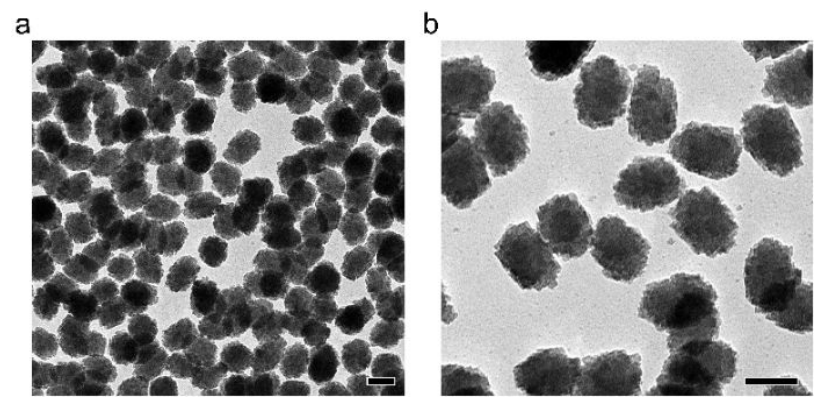

Figure S1. TEM images of the original $\beta$-FeOOH ellipsoids. Scale bars: $100 \mathrm{~nm}$.
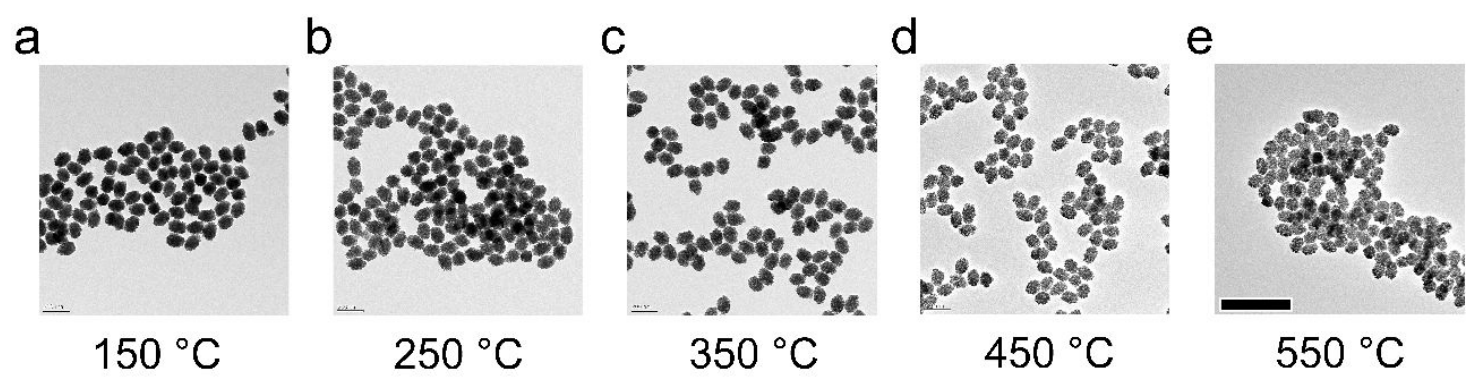

Figure S2. TEM images of the PAA-modified $\beta$-FeOOH ellipsoids calcined at various temperatures for $2 \mathrm{~h}$. Scale bar: $500 \mathrm{~nm}$.

a
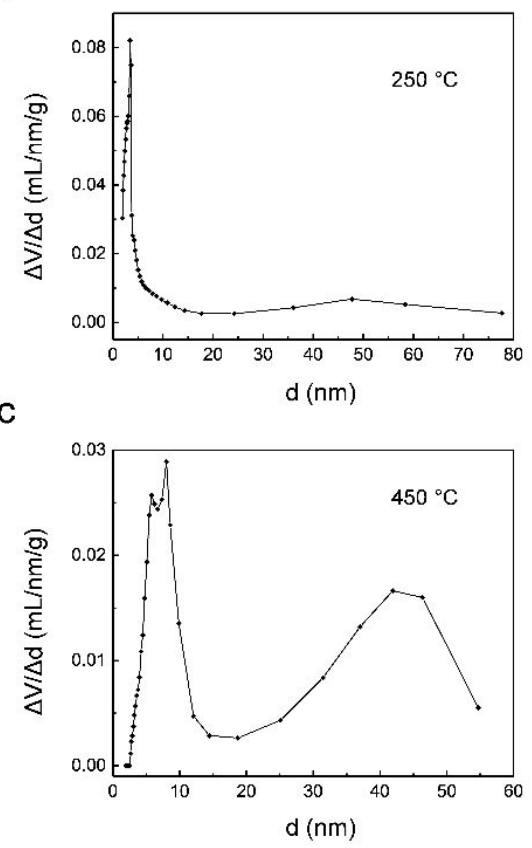

b
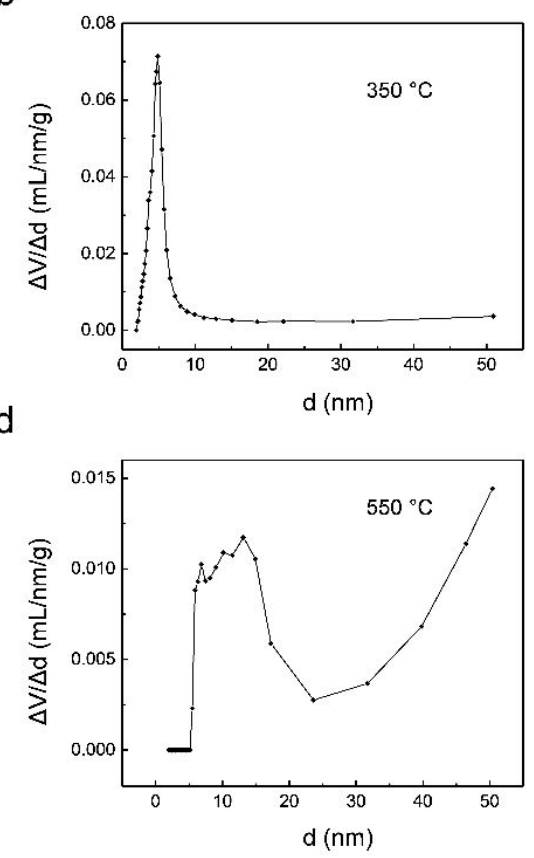

Figure S3. Pore size distribution curves of PAA-modified $\beta-\mathrm{FeOOH}$ ellipsoids calcined at various temperatures for $2 \mathrm{~h}$. 


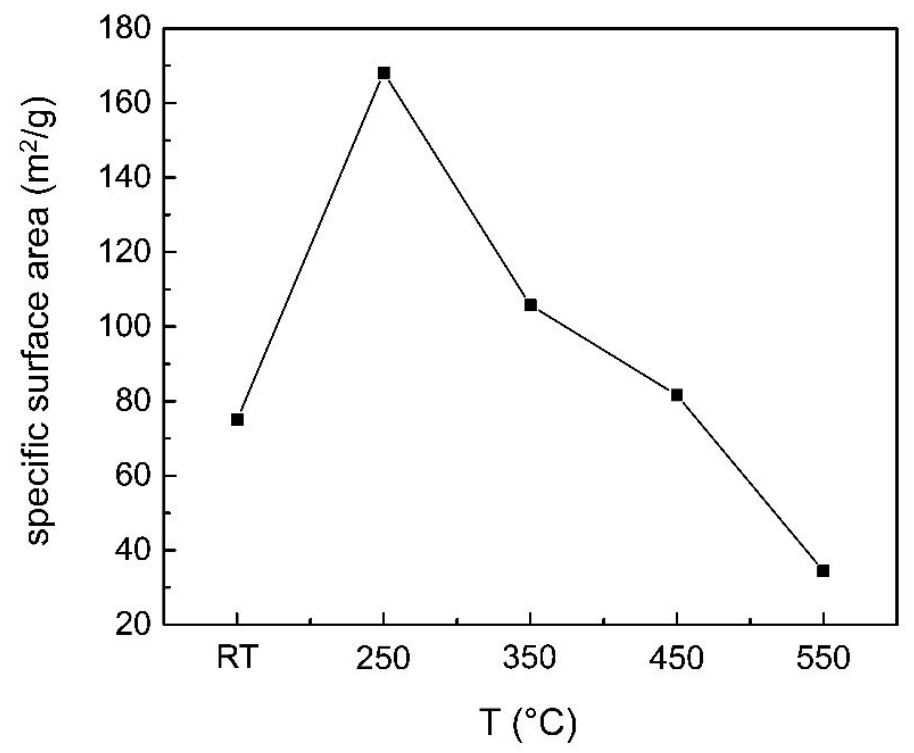

Figure S4. Specific surface area of the original $\beta-\mathrm{FeOOH}$ ellipsoids and the samples calcined in air at various temperatures for $2 \mathrm{~h}$.

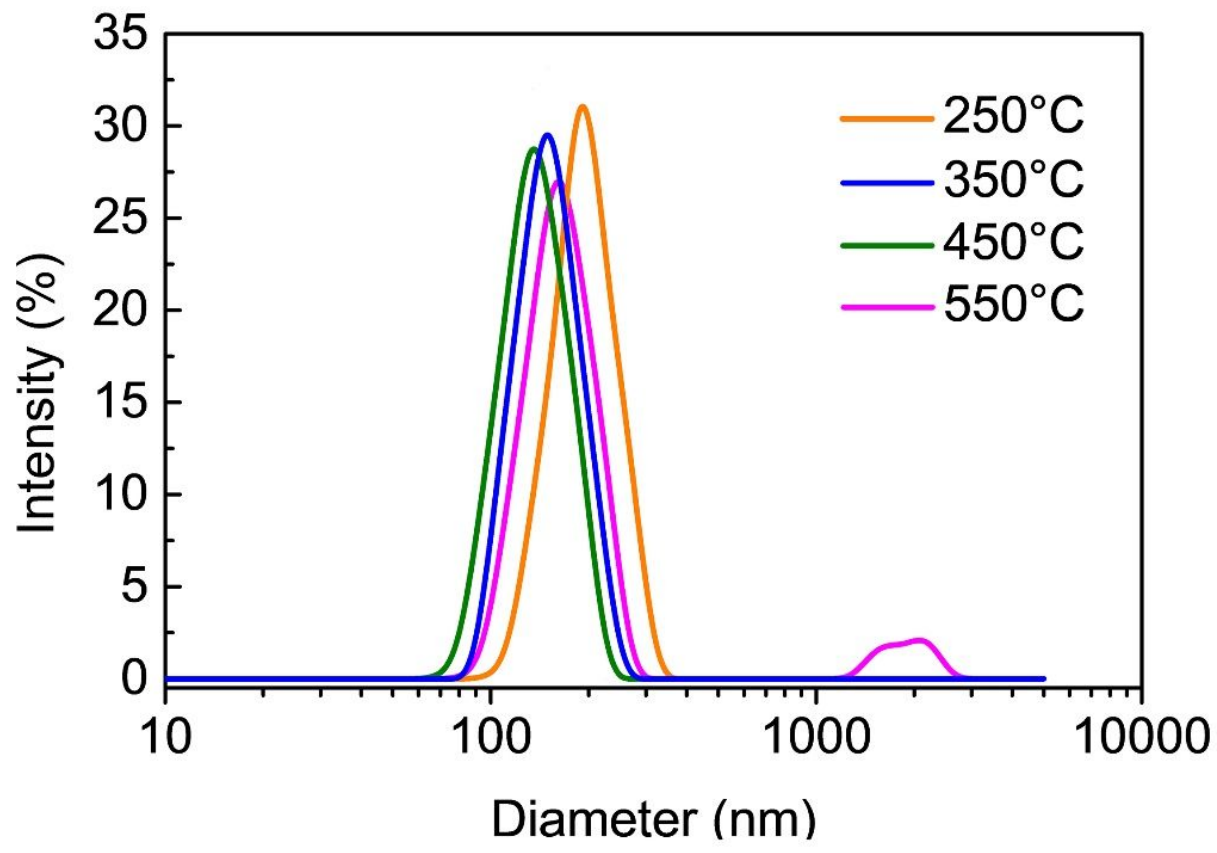

Figure S5. The size distributions of PAA-modified ellipsoids calcined for $2 \mathrm{~h}$ at $250{ }^{\circ} \mathrm{C}, 350{ }^{\circ} \mathrm{C}$, $450{ }^{\circ} \mathrm{C}$ and $550{ }^{\circ} \mathrm{C}$. 

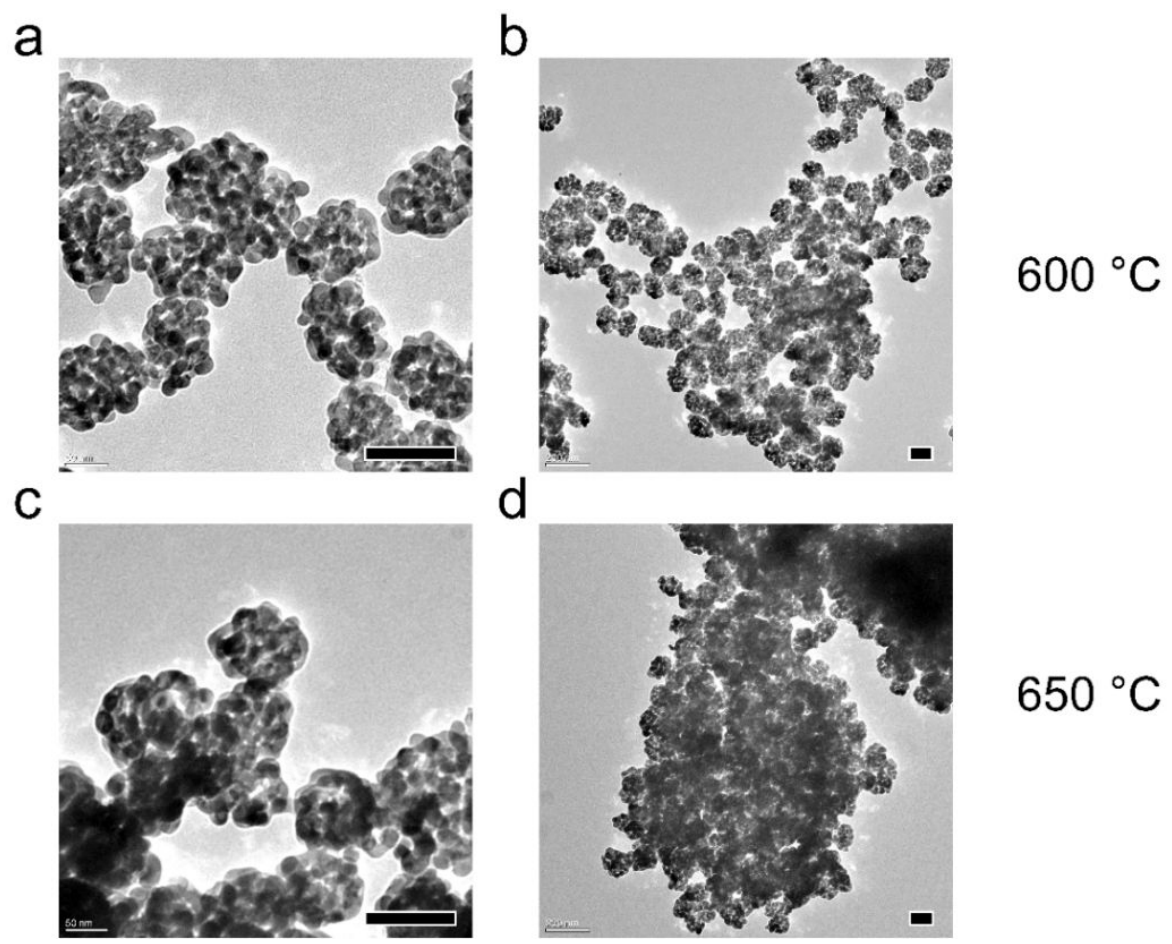

Figure S6. Morphologies of the $\beta$-FeOOH ellipsoids calcined at $600{ }^{\circ} \mathrm{C}$ (a and b) and $650{ }^{\circ} \mathrm{C}(\mathbf{c}$ and d) for $2 \mathrm{~h}$. Scale bars: $100 \mathrm{~nm}$.

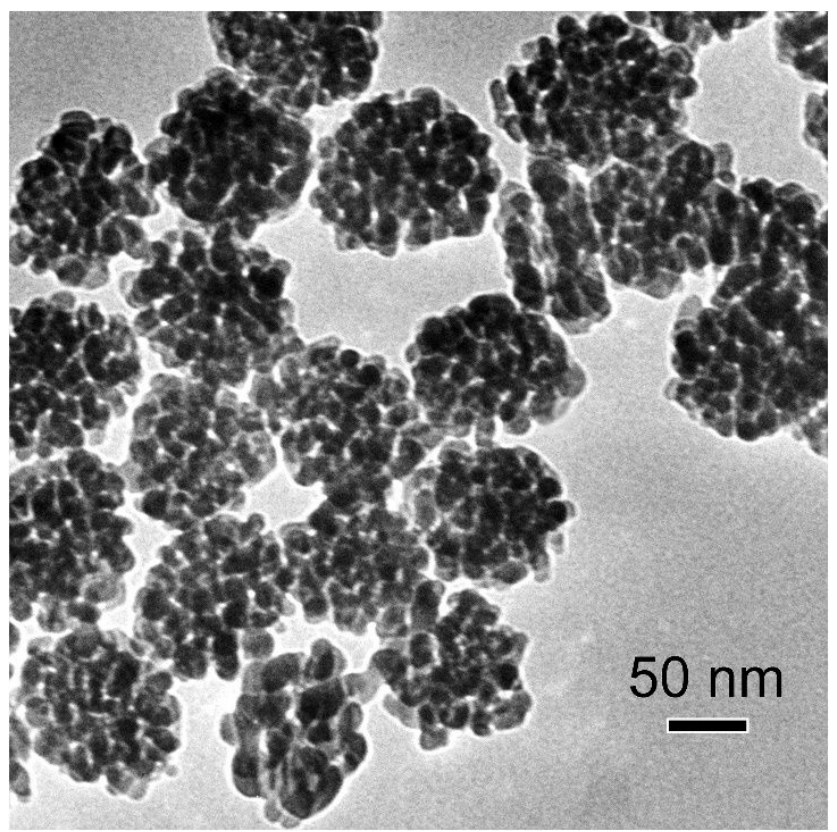

Figure S7. TEM image of the $\mathrm{Fe}_{2} \mathrm{O}_{3}$ ellipsoids with a secondary PAA modification calcined in air at $550{ }^{\circ} \mathrm{C}$ for $2 \mathrm{~h}$. 

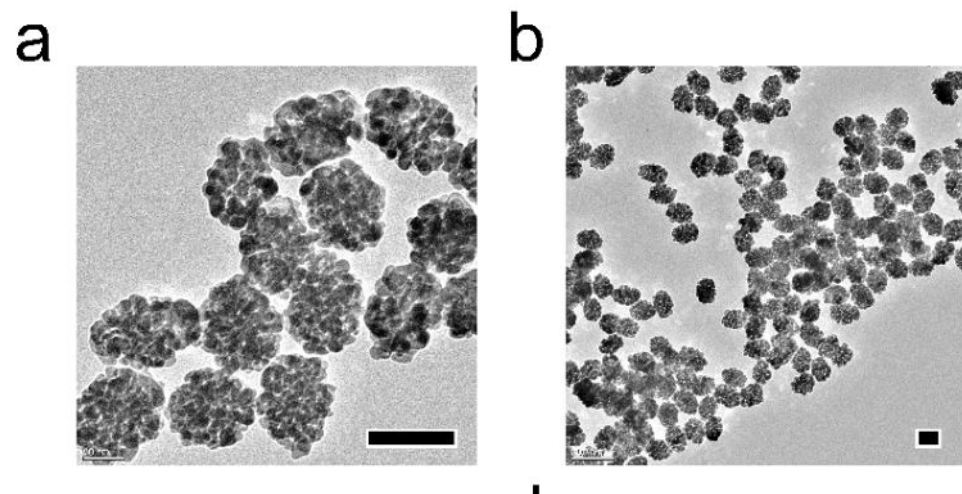

\section{0}

C

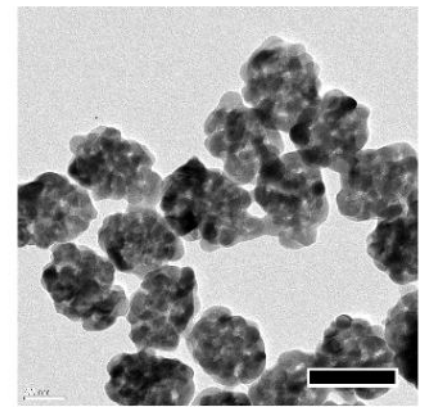

d

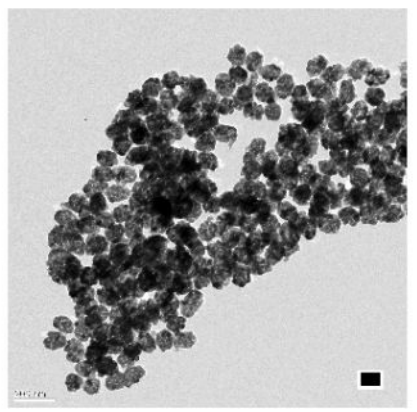

\section{0}

Figure S8. PAA with a molecular weight of 5000 (a and b) and 100,000 (c and d) were used to modify the FeOOH ellipsoids. Then these nanoparticles were calcined at $600{ }^{\circ} \mathrm{C}$ for $2 \mathrm{~h}$. Scale bars: $100 \mathrm{~nm}$.

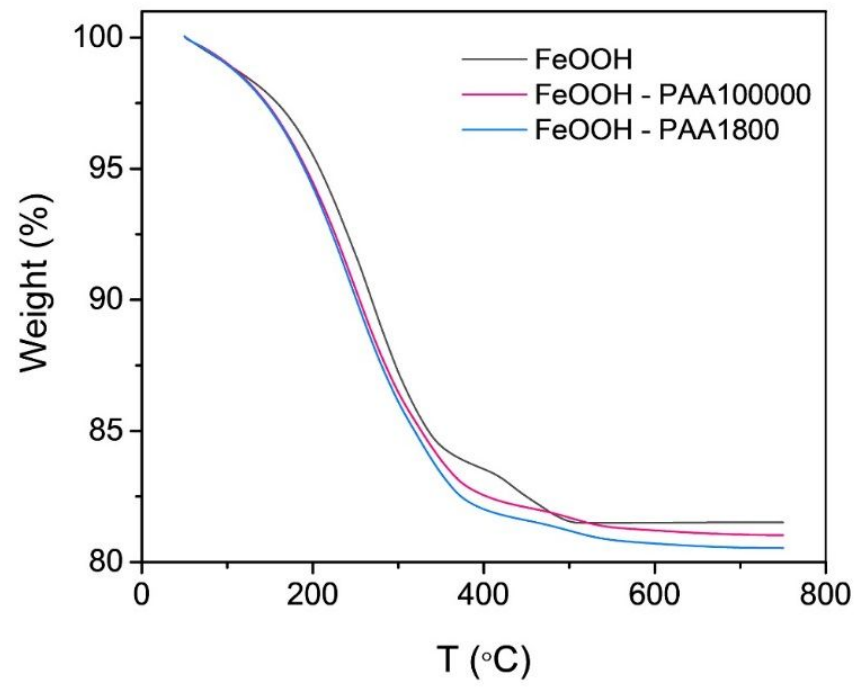

Figure S9. TGA measurements of $\mathrm{FeOOH}$ ellipsoids and $\mathrm{FeOOH}$ ellipsoids modified by PAA with molecular weight of 1800 and 100000. 


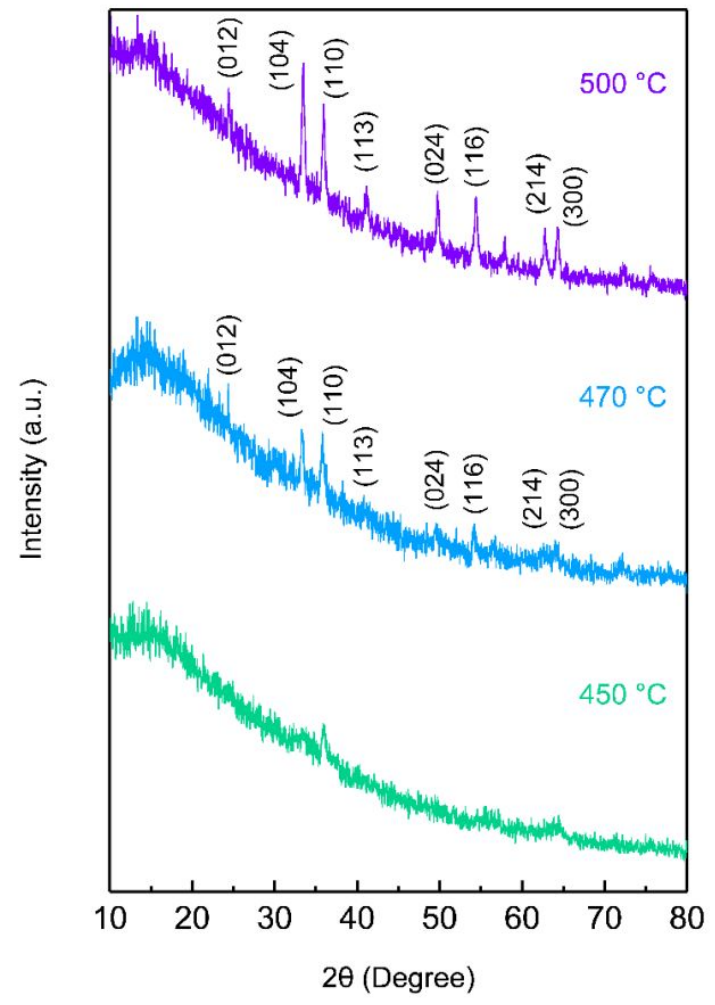

Figure S10. XRD patterns of PAA-modified $\beta$-FeOOH ellipsoids calcined at $450{ }^{\circ} \mathrm{C}, 470{ }^{\circ} \mathrm{C}$, and $500{ }^{\circ} \mathrm{C}$.

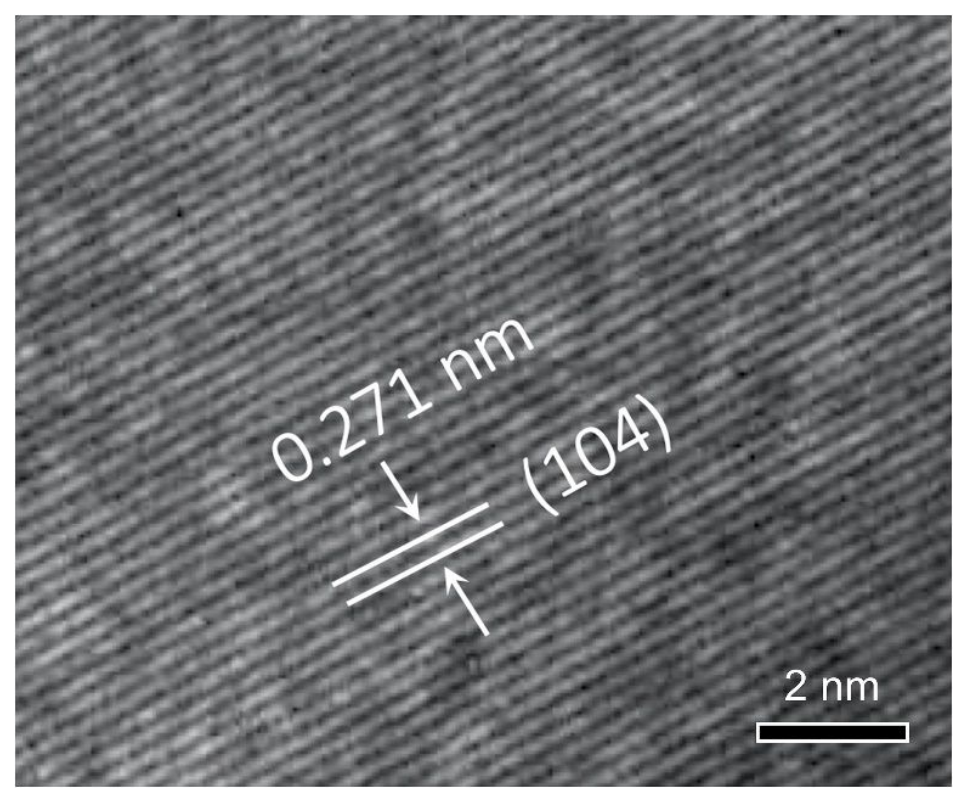

Figure S11. HRTEM image of $\mathrm{Fe}_{2} \mathrm{O}_{3}$ ellipsoids. 
a

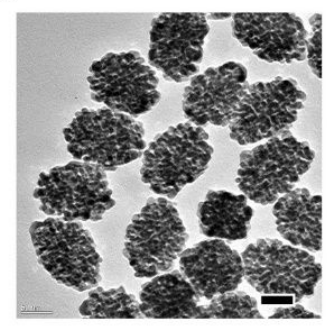

PSS b

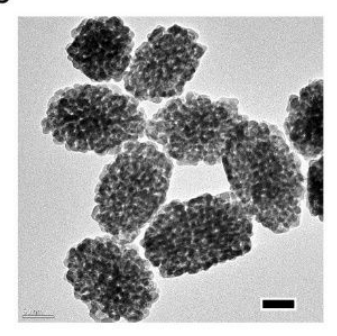

polyallylamine
C

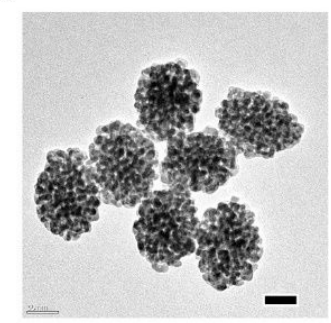

PVP

Figure S12. $\beta$-FeOOH ellipsoids were modified by PSS (a), polyallylamine (b) and PVP (c) and then calcined at $350{ }^{\circ} \mathrm{C}$ for $2 \mathrm{~h}$. Scale bars: $50 \mathrm{~nm}$.

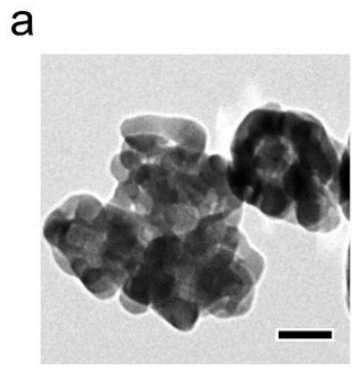

PSS b

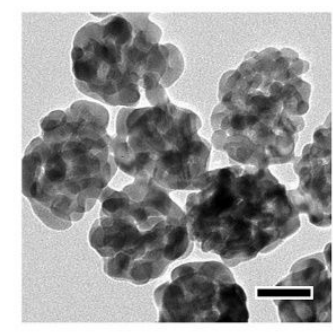

polyallylamine
C

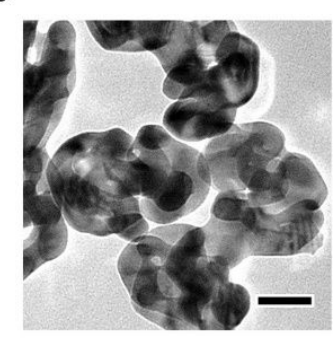

PVP

Figure S13. $\beta$-FeOOH ellipsoids were modified by PSS (a), polyallylamine (b) and PVP (c) and then calcined at $550{ }^{\circ} \mathrm{C}$ for $2 \mathrm{~h}$. Scale bars: $50 \mathrm{~nm}$.

a

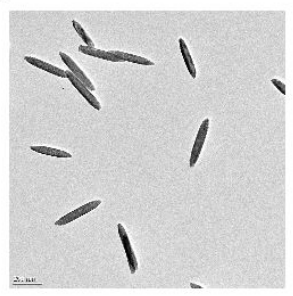

$250{ }^{\circ} \mathrm{C}$ b

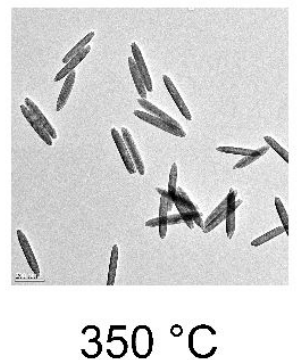

C

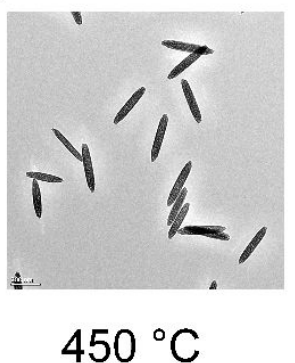

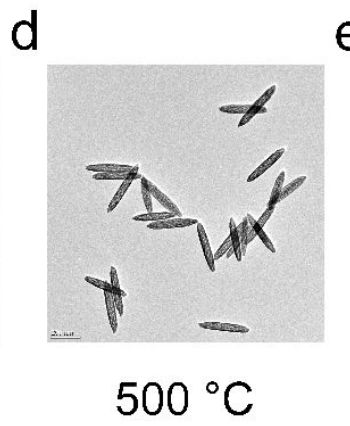

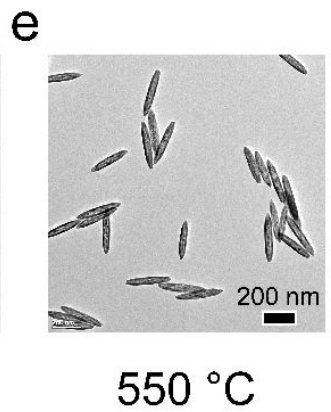

Figure S14. The morphology evolution of the $\beta-\mathrm{FeOOH}$ rods after calcination for two hours at a gradient temperature from $250^{\circ} \mathrm{C}$ to $550{ }^{\circ} \mathrm{C}$ with an interval of $100{ }^{\circ} \mathrm{C}$. 


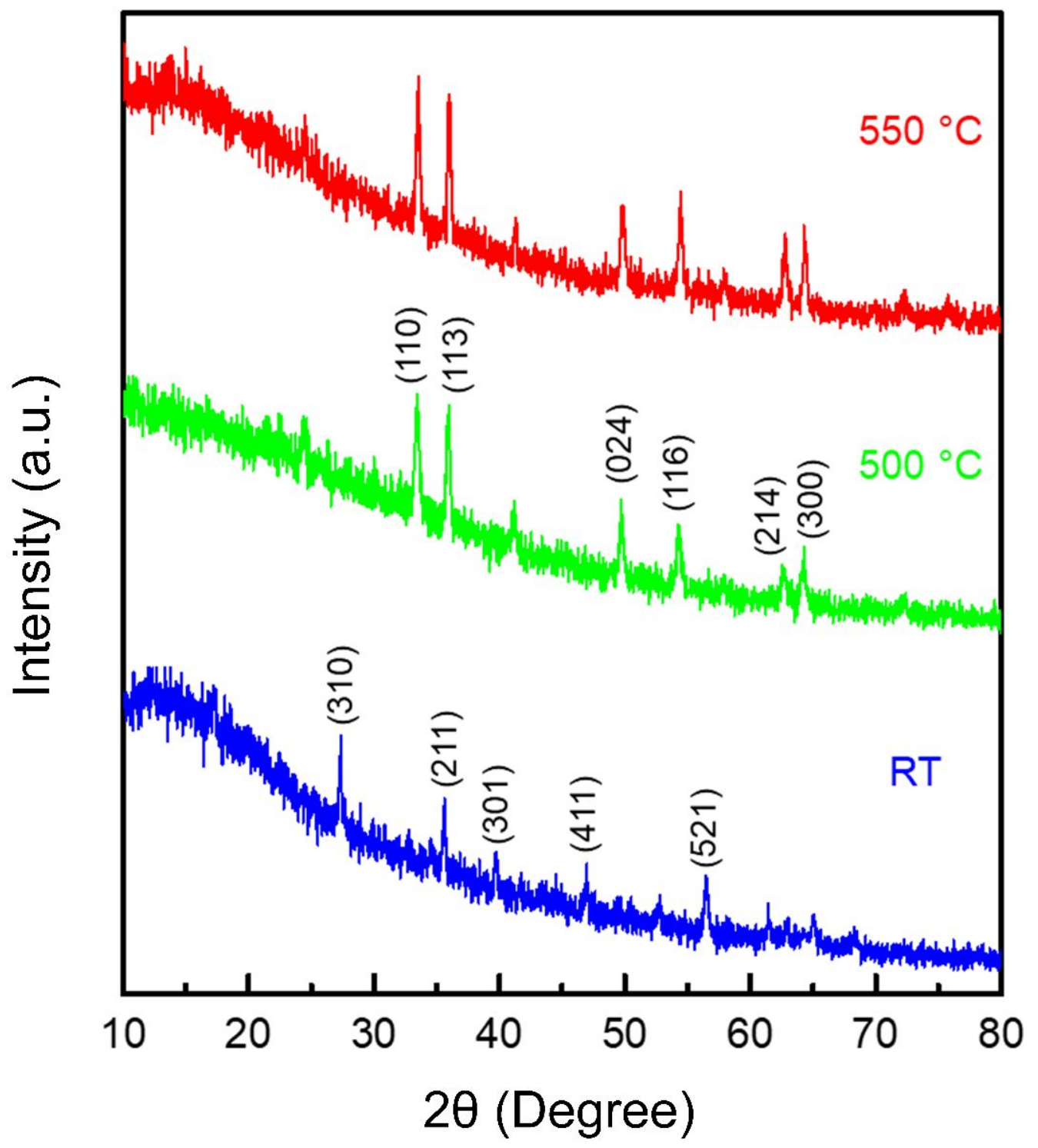

Figure S15. XRD patterns of PAA-modified $\beta$-FeOOH rods and the samples calcined at $500{ }^{\circ} \mathrm{C}$ and $550{ }^{\circ} \mathrm{C}$. 

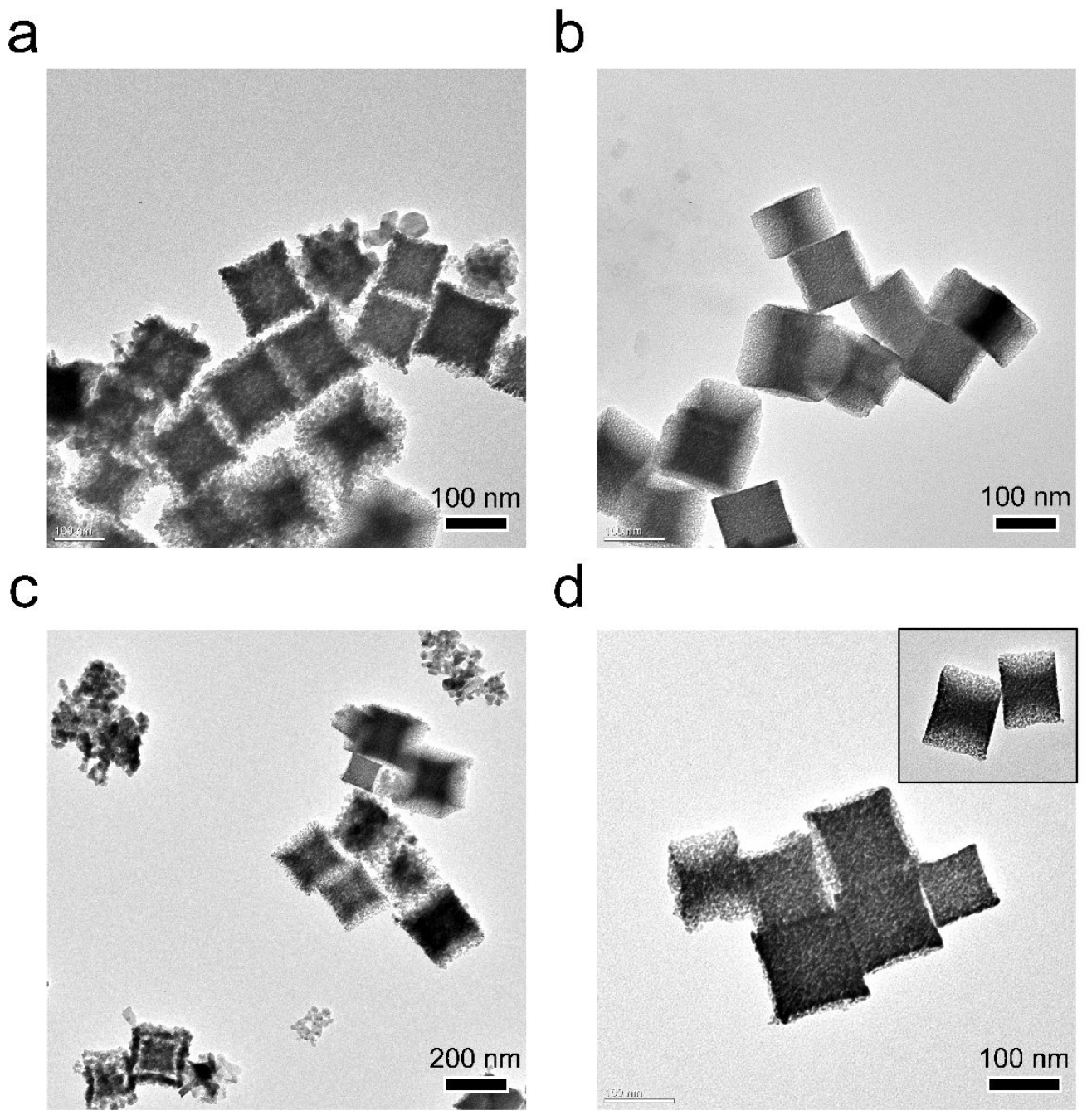

Figure S16. a and $\mathbf{c}$ are TEM images of original PB nanocubes calcined at $250{ }^{\circ} \mathrm{C}$ and $350{ }^{\circ} \mathrm{C}$, respectively. $\mathrm{PB}$ nanocubes capped with PAA were also heated at $250{ }^{\circ} \mathrm{C}(\mathbf{b})$ and $350{ }^{\circ} \mathrm{C}(\mathbf{d})$.

a

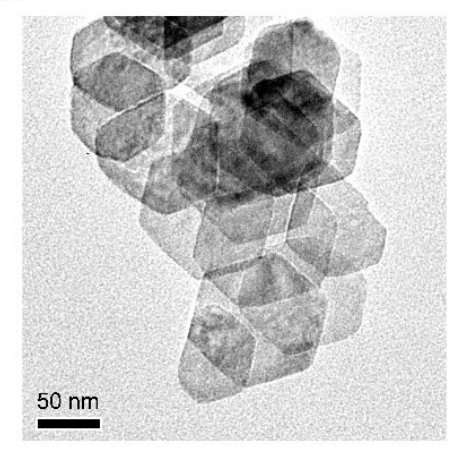

b

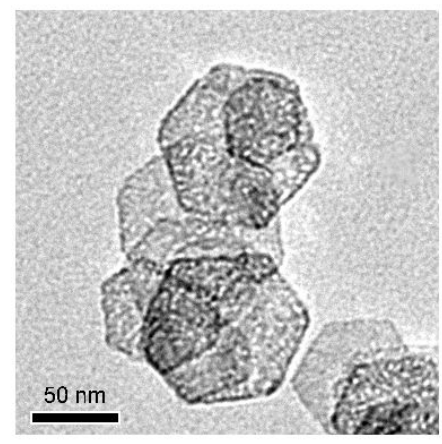

C

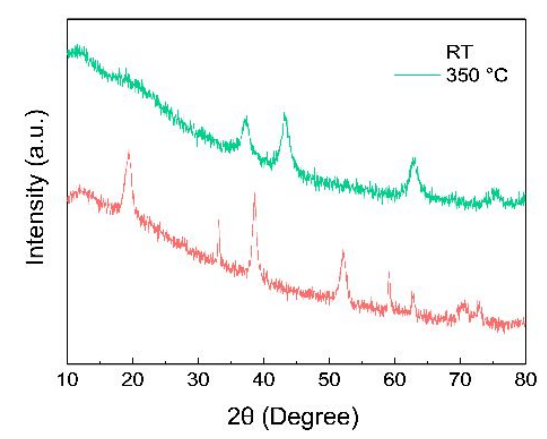

Figure S17. Morphology of PAA-modified $\mathrm{Ni}(\mathrm{OH})_{2}$ nanoplates before (a) and after (b) calcination at $350{ }^{\circ} \mathrm{C}$ for $2 \mathrm{~h}$. c, XRD patterns of PAA-modified $\mathrm{Ni}(\mathrm{OH})_{2}$ nanoplates annealed at $350{ }^{\circ} \mathrm{C}$. 


\section{$\mathrm{FeOOH} @ \mathrm{PAA} \stackrel{\text { Reduction }}{\longrightarrow} \mathrm{Fe}_{3} \mathrm{O}_{4}$}

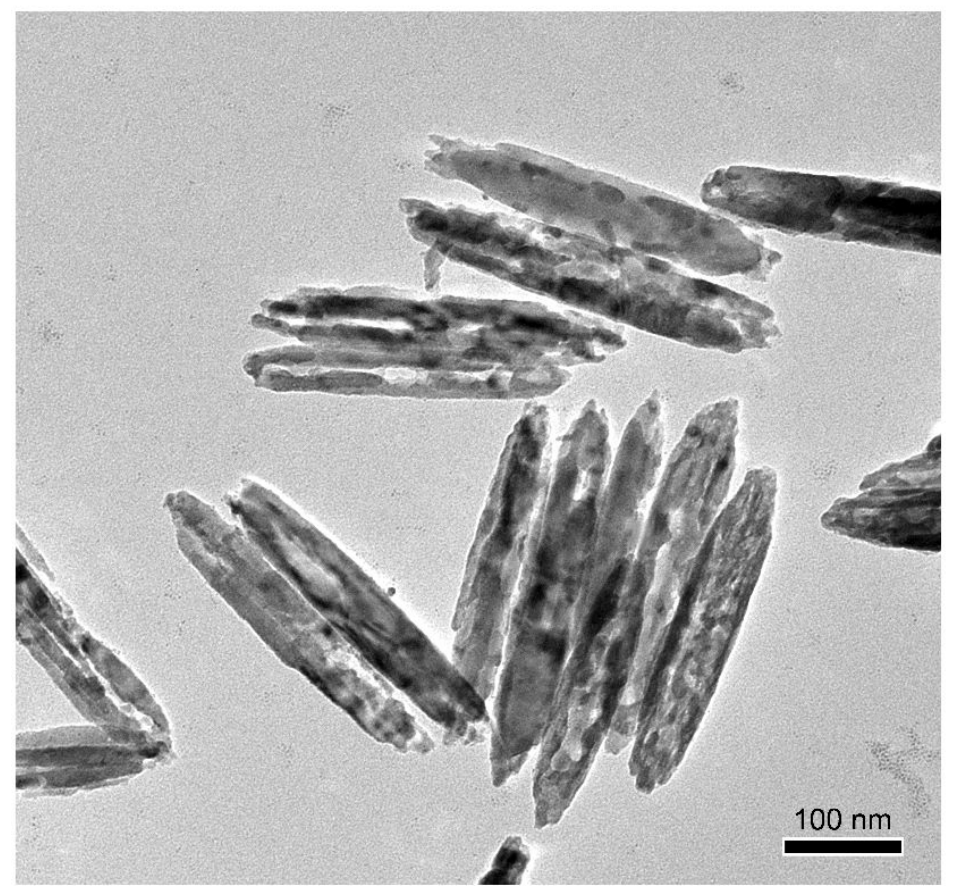

Figure S18. Direct reduction of PAA-modified FeOOH rods in forming gas at $330^{\circ} \mathrm{C}$ for $2 \mathrm{~h}$.

a
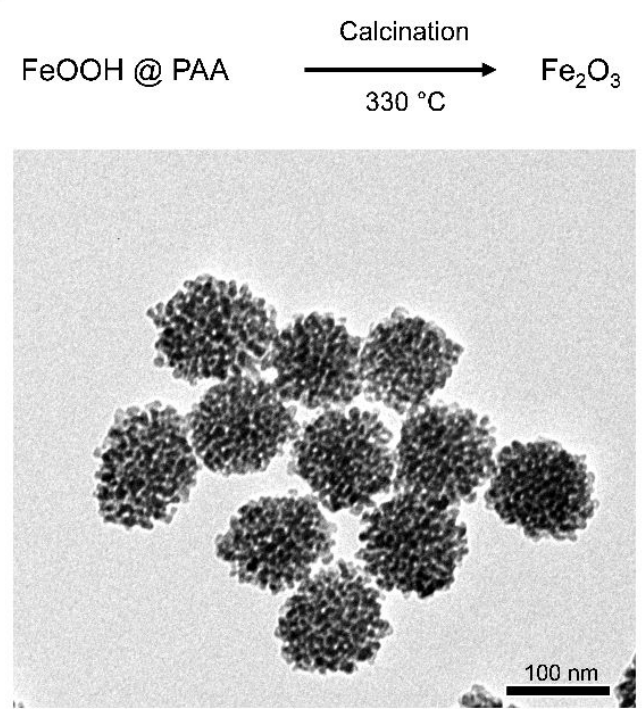

b
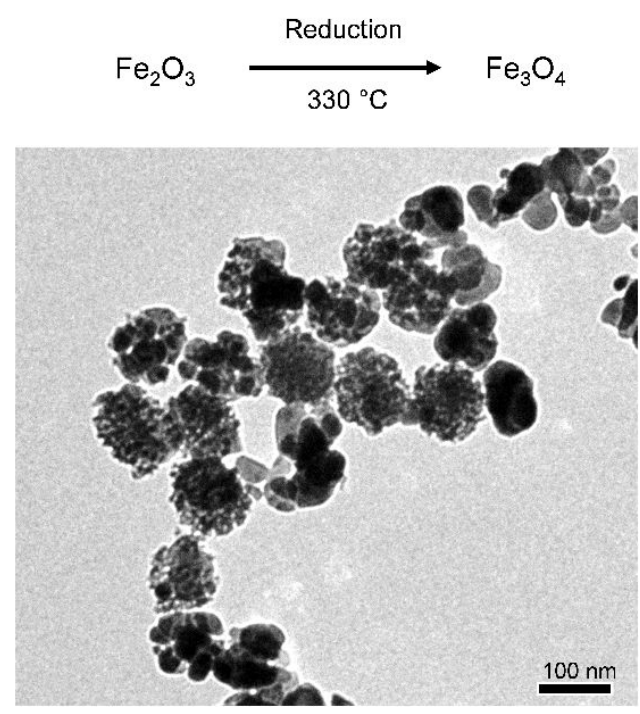

Figure S19. PAA-modified FeOOH ellipsoids were heated in air at $330{ }^{\circ} \mathrm{C}$ for $2 \mathrm{~h}$. Then the obtained nanoparticles (a) were reduced in forming gas directly without a secondary PAA modification (b). 


\section{References:}

1. Wang, M.; He, L.; Xu, W.; Wang, X.; Yin, Y. Angew Chem Int Ed Engl 2015, 54, (24), 7077-81.

2. $\quad$ Maeda, Y.; Hachisu, S. Colloids and Surfaces 1983, 6, (1), 1-16.

3. Hu, M.; Furukawa, S.; Ohtani, R.; Sukegawa, H.; Nemoto, Y.; Reboul, J.; Kitagawa, S.; Yamauchi, Y. Angew Chem Int Ed Engl 2012, 51, (4), 984-8.

4. $\quad$ Liu, Z.; Ma, R.; Osada, M.; Takada, K.; Sasaki, T. J Am Chem Soc 2005, 127, (40), 13869-74.

5. Durand-Keklikian, L.; Haq, I.; Matijević, E. Colloids and Surfaces A: Physicochemical and Engineering Aspects 1994, 92, (3), 267-275. 